\title{
RETÓRICAS ESPAÑOLAS DEL SIGLO XVI EN LA BIBLIOTECA NACIONAL DE MADRID
}

\author{
M. A. Garrido, A. L. LujÁn, \\ L. Alburquerque, M. A. Martínez \\ Instituto de Filología. CSIC
}

\begin{abstract}
Abordamos en estas páginas una completa revisión de los originales de retóricas del siglo XVI que se encuentran en la Biblioteca Nacional de Madrid a efectos del cumplimiento de un propósito en el que está laborando nuestro grupo. Como culminación del proyecto en marcha titulado Corpus retórico español, se trata de propiciar, en colaboración con otros grupos y personas singulares interesados en estos trabajos, la publicación en CD ROM de aquellas retóricas entre las mencionadas que no disponen de una edición moderna. Ofreceremos en su día el texto original de cada una, su traducción castellana (cuando, como ocurre casi siempre, estén en latín) así como las correspondientes introducciones y notas aclaratorias. La finalidad es mantener en estado de vigilia una parte de nuestro rico legado cultural, que es menos manejada de lo que debiera a causa del alejamiento que para muchos produce la lengua en que está escrita (el latín) y el lenguaje (la cultura) a que responde (el Humanismo). Estos objetivos se inscriben en un clima de recuperación de la retórica que pasamos a comentar y en un marco español cuyas coordenadas también exponemos.
\end{abstract}

\section{El AUGE DE LA RETÓRICA}

Como ha documentado admirablemente José Antonio Mayoral en un reciente trabajo ${ }^{1}$, la revitalización de la venerable disciplina llamada Retórica es un hecho en la institución académica española y universal ${ }^{2}$.

\footnotetext{
1 «La Retórica en los años 90. Algunas ideas y referencias para un estado de la cuestión de los estudios retórico-literarios», Glosa, 6, 1995, págs. 91-123.

${ }^{2}$ Cfr. J. M. Pozuelo Yvancos, Del Formalismo a la Neorretórica, Madrid, Taurus, 1988.
} 
Resulta ahora natural que una materia que de modo constante formó parte de la ratio fundamental de los estudios occidentales desde la antigüedad clásica hasta nuestros días, pasando por su cristalización medieval, vuelva a ser atendida. No era pensable que una dedicación tan universal y constante estuviera carente de fundamento ${ }^{3}$.

Es bien sabida su historia y cómo el resquebrajamiento de la metafísica que le servía de base fue propiciando a partir del nominalismo del siglo XIV su paulatina debilidad, aumentada con el antropocentrismo renacentista ${ }^{4}$ hasta llegar a ser borrada por los sucesivos embates de racionalismo y romanticismo que la dejó reducida en las publicaciones de comienzos del siglo $\mathrm{xx}$ a prontuarios insustanciales que prolongaban una vieja inercia o, sobre todo, a inertes listados de las figuras retóricas ofrecidos como apéndices en los manuales de literatura.

Sin embargo, apenas desaparecida, volvió a renacer de sus cenizas. En los años cincuenta, Perelman y otros volvieron su mirada al interés que atesoraba la Retórica como ciencia de la argumentación ${ }^{5}$. En los sesenta, Lausberg ofreció la sistematización de la doctrina clásica en su Manual de retórica literaria ${ }^{6}$ cuyo título señala una apreciación de raigambre aristotélica: las reglas que sirven para hacer atrayente el discurso con el fin de conseguir la persuasión deben ser las mismas, al menos en parte, que se utilizan para llamar la atención con una finalidad estética. A partir de aquí se multiplicaron nuevas descripciones retóricas elaboradas con las metodologías estructuralistas que, procedentes de la lingüística, habían entrado a formar parte del acervo común del que disponía la nouvelle critique de entonces. El manual de elocutio retórica confeccionado por el grupo de la Universidad de Lieja en $1970^{7}$ supuso la señal de salida de una carrera que no se ha detenido aún. Hasta hoy sigue, en efecto, el interés por la doble vertiente señalada, la relación de la retórica tanto con la teoría literaria ${ }^{8}$ como con su genuina función de formación de oradores ${ }^{9}$. Podemos comprobarlo, repasan-

\footnotetext{
${ }^{3}$ Cfr. T. Albaladejo, «Retos actuales de la retórica», en I. Paraíso (ed.), Retos actuales de la teoría literaria, Valladolid, Universidad, 1994, págs. 51-60; J. A. Hernández Guerrero y M. ${ }^{a}$ C. García Tejera, Historia breve de la Retórica, Madrid, Síntesis, 1994; A. López Eire, Actualidad de la Retórica, Salamanca, Universidad, 1995.

${ }^{4}$ Cfr., por ejemplo, el significado del «ramismo» como escuela de retórica en el siglo xvI: W. J. Ong, Ramus. Method and the Decay of Dialogue, Cambridge, Mass., Harvard University Press, 1958. $1989^{4}$.

Vid. C. Perelman y L. Olbrechts-Tyteca, Tratado de la argumentación, Madrid, Gredos,

${ }^{6}$ Madrid, Gredos, 1966-7, 3 vols.

${ }^{7}$ Grupo $\mu$, Retórica general, Barcelona, Paidós, 1987.

${ }^{8}$ Cfr. A. López Eire, Retórica clásica y teoría literaria moderna, Madrid, Arco/Libros, 1997.

9 Cfr. A. Ortega Carmona, Retórica. El Arte de hablar en público, Madrid, Fundación Cánovas del Castillo, 1997.
} 
do a continuación más detenidamente los diversos aspectos de este auge y tomando por ejemplo las publicaciones realizadas entre nosotros en el último lustro.

El desarrollo de la elocutio está vinculado, sin duda, al nacimiento de la poética lingüística, hija del estructuralismo en crítica literaria. Cuando el foco de la pregunta sobre el fenómeno literario se centra en el cómo está hecha la obra, la respuesta se limita a cuestiones de estilo: se trata de examinar los principios constructivos que se han puesto en funcionamiento hasta dar lugar a la estructura de que se trate. Sobre eso versaba precisamente la elocución en la disciplina retórica y, de ahí, la proliferación de nuevos listados de figuras, como el citado de la Escuela de Lieja, basados en diversos modelos explicativos.

Ciertamente, la concepción del ornatus como algo superpuesto a guisa de adorno externo (flores rhetoricales) es totalmente ajena a la visión estructuralista que aborda el conjunto textual como un todo unitario de elementos mutuamente implicados. Son los mismos fenómenos de siempre, pero no se explican por el estructuralismo de manera igual. No obstante, la objetividad de hecho en los fenómenos inventariados (tropos y figuras) hace que los listados sean casi idénticos a pesar también de los cambios de denominaciones, debido a los cuales encontramos un mismo término aplicado a dos o más fenómenos distintos en diversos trabajos, o diversos términos que recubren en sus respectivos listados una misma definición. Es preciso, por consiguiente, estar especialmente atento al contexto y situación a que pertenecen los términos que se estén empleando.

Además de la constante presencia del manual de Kurt Spang $(1979)^{10}$, hay que señalar el importante tratado de José Antonio Mayoral ${ }^{11}$, los libros escolares de Azaustre y Casas $^{12}$ y el de José Luis García Barrientos ${ }^{13}$ como demostración de esa continuidad de que venimos hablando. Lejos de haber desaparecido del todo como se presagiaba a principios de siglo, a finales del $\mathrm{xx}$ los elencos de esquemas y licencias se tienen por indispensables. Podríamos decir, incluso, de acuerdo con José Antonio Mayoral, que parece excesiva la atención prestada al fenómeno de los tropos en general y la metáfora en particular a juzgar por la ingente cantidad de títulos que recogen los inventarios bibliográficos confeccionados al efecto. También debemos mostrarnos de acuerdo en que «sería más que deseable emprender análisis pormenorizados de los otros muchos fenómenos asociados a figuras concre-

\footnotetext{
${ }^{10}$ Fundamentos de retórica literaria y publicitaria, Pamplona, Eunsa, $1997^{4}$.

1 Figuras retóricas, Madrid, Síntesis, 1994.

12 A. Azaustre y J. Casas, Manual de retórica española, Barcelona, Ariel, 1997.

${ }^{13}$ Las figuras retóricas, Madrid, Arco/Libros, 1998.
} 
tas o grupos de figuras afines [...] así como el del funcionamiento de cada figura o grupo de figuras en el espacio concreto de los textos» ${ }^{14}$.

Añadamos que la apertura semiótica de estos estudios reclama el inventario de los fenómenos correspondientes (idiomático o no) que proliferan en el mundo de la publicidad (discurso persuasivo de nuestro tiempo, o sea, genuinamente retórico) en el que cabe señalar tanto paralelismos evidentes entre mensajes gráficos y lingüísticos, como discordancias también indudables. Un epítome de Antonio Ferraz ${ }^{15}$ se ha ocupado recientemente de la cuestión.

El giro pragmático emprendido por la ciencia del lenguaje ha sido otro factor que trae al primer plano la retórica. En efecto, el planteamiento retórico no se centra primeramente en el enunciado, sino en el proceso de enunciación. El orador debe calibrar la situación de su público, sus presuposiciones, sus compromisos epistemológicos, si quiere lograr un acto comunicativo retóricamente pleno, es decir, que acabe en la persuasión. El enunciado que profiere será fuertemente connotativo y se interpretará según claves contextuales y no sólo de un código lingüístico en sentido abstracto, pretendidamente compartido también en abstracto por todos.

Siendo esto así, la retórica conecta con las perspectivas actualmente más cultivadas de la lingüística y de la teoría de la literatura ${ }^{16}$. La teoría de los actos del lenguaje y las demás opciones de pragmática rompen el cerco del enunciado en el que habían encerrado a la lingüística ciertos estructuralismos, y se encuentran de nuevo con unos planteamientos que son mutatis mutandis los de la vieja retórica. La teoría de la literatura, por su parte, se pregunta por el sentido proveniente de la situación comunicativa (la fuerza ilocutiva) que otorga el significado literario, ficcional, a ciertos textos y permite unas leyes de intercambio que anulan las condiciones de veracidad y otras, obligatorias en las restantes situaciones de la comunicación.

Nótese que no se trata ahora sólo de la elocutio, de las listas de figuras ejemplificadas con textos literarios, según lo que decíamos antes de su perduración como la más clara consecuencia de la semejanza entre el tipo de elaboración del enunciado emprendido con fines persuasivos y el emprendido con fines estéticos. Trátase ahora, en cambio, de una concepción de la teoría literaria coincidente en todo con el modelo retórico de un proceso de enunciación en el que la elocutio es sólo una de las partes. Se convierte así la literatura en uno más de los genera de los que entiende la retórica en general.

\footnotetext{
${ }^{14}$ J. A. Mayoral, art. cit., pág. 111.

15 El lenguaje de la publicidad, Madrid, Arco/Libros, 1993.

16 Vid. A. García Berrio, "Sobre la Retórica general como ciencia de la expresividad artística», en Teoría de la literatura, Madrid, Cátedra, págs. 140-179.
} 
Dicho de otra manera, la poética general se concibe en este extremo como una especie de retórica a diferencia de la llamada poética lingüística que, insistimos, se veía como parte de la retórica, aquella que suponía un ámbito de intersección entre los dos territorios, autónomos cada uno, de la retórica y la poética.

Sin duda, esta identidad de fondo encontrada entre poética y retórica ha sido otra de las causas que desde el ámbito de los teóricos literarios ha despertado un nuevo interés por esta segunda disciplina, la cual, por lo demás, no resultaba ajena a los poetólogos en virtud de su constante presencia en la historia de los períodos culturales que todos han debido atender en cuanto estudiosos de la literatura y, por tanto, en una u otra medida, de su periodización. Precisamente de los historiadores de la literatura proviene la advertencia de otra posible utilidad de la retórica que ha llamado la atención en los últimos tiempos a muchos de ellos y que a continuación abordaremos.

La Retórica, como cualquier doctrina, se puede plantear de forma deductiva o inductiva. Cabe proponer unos esquemas de comunicación según los cuales se lograría un acto retórico y cabe, por otra parte, extraer las reglas implícitas en los actos retóricos de hecho logrados. Naturalmente, existe una relación circular entre ambos extremos: quien profiere el discurso se atiene a ciertos principios más o menos conscientemente consabidos y quien enuncia un modelo tiene en cuenta, de forma más o menos explícita, los datos de hecho que avalan la hipótesis.

Hay quienes han entendido que los modelos teóricos de la retórica literaria son las matrices generadoras de los discursos literarios producidos. Argumentan que, sobre todo durante el largo período en que la retórica ha formado parte de la educación fundamental, los autores literarios que la han aprendido, la habrán tenido en cuenta al hacer sus composiciones. Concluyen, en fin, que aplicando la plantilla retórica a cada una de las obras, se obtendrá un análisis que mostrará a partir de qué instancias se ha generado el texto ${ }^{17}$. Puede no faltarles razón en algunos casos determinados.

No obstante, hay que tener en cuenta que los mecanismos expuestos por la poética y la retórica teóricas, sean hipótesis abstractas o deducciones de determinadas prácticas, ilustran modos humanos de comunicar $\mathrm{y}$, en ese sentido, es natural que coincidan esquemas previos y estructuras de los discursos sin necesidad de que aquéllos se hayan tenido en cuenta al confeccionar éstos. La historia ilustra más bien lo contrario. El autor escribe de forma espontánea y, si es el caso, justifica a posteriori sus escritos con las

${ }^{17}$ Cfr. L. López Grigera, «La retórica como código de producción y de análisis literario», en La Retórica en la España del Siglo de Oro. Teoría y práctica, Salamanca, Universidad, 1994, págs. 17-32. 
fórmulas que dice aceptar, forzando su interpretación, si hace falta, para que la adecuación se sostenga. El Arte Nuevo de Hacer Comedias de Lope de Vega no es más que un renombrado caso palmario en el paralelo campo de la poética y entre muchísimos otros.

Elena Artaza señala, a propósito de las diferencia entre ciceronianos y hermogenistas en nuestras retóricas del siglo XVI, que «las teorías hermogénicas explicadas por Núñez son ejemplificadas casi en su totalidad con textos ciceronianos, lo cual habla en favor de que dicha técnica puede servir de principio teórico a la praxis oratoria del gran modelo latino para la prosa» ${ }^{18}$. ¿No querrá esto decir que los discursos provienen de la competencia innata del hablante que se puede interpretar con los diferentes modelos ideados, ya ciceronianos, ya hermogenistas? Sería raro, si no, que resultara teóricamente «hermogenista» la práctica de Cicerón.

Nos parece un peligroso error, pues, el intento de generalizar este tipo de análisis retórico, lo cual no obsta para que pro opportunitate se pueda echar mano de él. En todo caso, este supuesto ha sido otra causa de la vuelta a la retórica que en estas líneas estamos justificando. Además, fuera de todo exceso, el análisis literario a partir de un fenómeno retórico bien identificado en los textos, sean conscientes o no de él los autores, puede producir obras tan estimables como las recientes de Pere Ballart ${ }^{19}$ o Fernando Romo ${ }^{20}$.

Por otra parte, la civilización de los medios de comunicación social ha traído como consecuencia una potenciación de la retórica (sin ese nombre) como quizás ninguna otra época de la historia. Con razón ha podido caracterizarse al ser humano de nuestro tiempo como «homo rhetoricus» ${ }^{21}$. Nada de extraño tiene, pues, que ese clima propicie también una nueva floración de estudios de retórica entre los que se cuentan los numerosísimos dedicados a la ya evocada publicidad. Ateniéndonos al panorama español que nos viene sirviendo de marco, en 1993 Juan Antonio Vallejo Nájera publicaba la edición vigésimosexta de su Aprender a hablar en público hoy ${ }^{22}$, aparición que ha ido acompañada o seguida de otros títulos como Comunicación oral en la empresa. Un enfoque retórico de B. O'C. Leggett ${ }^{23}$, Oratoria. El arte de hablar, disertar, convencer

\footnotetext{
${ }^{18} C f r$. E. Artaza, Antología de textos retóricos españoles del siglo XVI, Bilbao, Universidad de Deusto, 1997, pág. 21.

19 Eironeia: la figuración irónica en el discurso literario moderno, Barcelona, Sirmio,

20 Retórica de la paradoja, Barcelona, Octaedro, 1995.

21 Cfr. M. A. Garrido Gallardo, La Musa de la Retórica. Problemas y Métodos de la Ciencia de la Literatura, Madrid, CSIC, 1994, págs. 183-197.

22 Barcelona, Planeta.

23 Pamplona, Eunsa, 1993.
} 1994. 
de Jürg Studer ${ }^{24}$, El Arte de hablar bien y convencer. Platón, Aristóteles, Cicerón. Manual del Orador, edición de textos clásicos realizada por Santiago A. López Navia ${ }^{25}$ o Curso práctico de técnicas de comunicación oral de Arturo Merayo ${ }^{26}$ para una colección de temas de actualidad. Parece indiscutible que el clima de la cultura de la «imagen» tiene también su parte en este auge.

Sostiene Miguel Ángel Garrido en las páginas citadas que el nominalismo ${ }^{27}$, que ha venido disolviendo a partir del siglo XIV las convicciones metafísicas subyacentes en la retórica tradicional, ha tenido un doble efecto sobre la vigencia de la disciplina. Primeramente, el clima de la llamada cultura moderna (y postmoderna) ha dejado sin suelo una retórica que contaba con una lógica y una ontología sólidas, al menos como contraste. En la actualidad, en la sociedad sin convicciones, en la cultura dominante en que han desaparecido los relatos completos que interpretaban el mundo, ha desaparecido la retórica-con-fundamento y sólo nos queda la retórica.

Como se ve, la cuestión propuesta es de calado distinto al de las otras influencias que hemos considerado. Después de todo, la resurrección de la retórica podría ser consecuencia de la misma causa que engendró su desaparición. La atención por los problemas institucionales y éticos que suscita desde el principio, tal como se recoge en la Institutio Oratoria de Quintiliano, se asentaría ahora en una razón distinta. Se trata de algo que ya suscitó Perelman en su momento ante el auge de una nueva cultura: ¿Se puede plantear la eficacia retórica como un fin absoluto? ¿Podemos basar nuestras convicciones en el asentimiento medido en medias estadísticas de encuestas? ¿Ha desaparecido la exigencia del «vir bonus» en la definición de vir bonus dicendi peritus que recogía Quintiliano?

Este aspecto del problema retórico enlaza con el de la virtualidad y límites de la cultura sofística. Nos parece que tiene que ver, en efecto, con el auge actual de la retórica y por eso lo traemos aquí. Sin embargo, el estudio de sus causas y consecuencias desborda, con mucho, el tenor de nuestro propósito en este trabajo según hemos dicho al principio, a saber, contribuir a satisfacer este interés de la comunidad intelectual, incorporando a la cultura viva textos ahora comúnmente fuera de la circulación.

\footnotetext{
${ }^{24}$ Madrid, El Drac, 1996.

${ }^{25}$ Madrid, Temas de Hoy, 1997.

${ }^{26}$ Madrid, Tecnos, 1998.

${ }^{27}$ Vid. K. Flasch, Einführung in die Philosophie des Buchgesellschaft, Darmstadt, Wissenschaftliche Buchgesellschaft, cap. IX, $1989^{2}$.
} 


\section{LA RECUPERACIÓN DEL LEGADO RETÓRICO EN ESPAÑA}

La recuperación próxima del legado retórico de la cultura española está ligada a la Historia de la ideas estéticas ${ }^{28}$ escrita por Menéndez Pelayo, quien desbroza, como había hecho en otros campos, el camino para un conocimiento minucioso del conjunto de retóricas que florecieron en el $\mathrm{Hu}$ manismo español de los siglos XVI y XVII. A partir de aquí, una serie de tesis universitarias posteriores han ido completando el panorama genera ${ }^{29} \mathrm{de}$ este conocimiento.

Mucho más tarde, en 1965, Antonio Martí presenta su tesis doctoral La retórica sacra en el siglo de Oro en la Facultad de Filosofía y Letras de la Universidad de Barcelona, obra que, convenientemente corregida, se publicó con el título La preceptiva retórica española en el Siglo de Oro ${ }^{30}$.

En 1971, José Rico Verdú defendió en la Universidad de Madrid la tesis doctoral titulada La retórica en el Siglo de Oro. Introducción al Humanismo, elaborada en el C.S.I.C ${ }^{31}$. Se trata de una descripción detallada de casi todas las retóricas del período y ofrece también los resúmenes de sus contenidos.

Tres años después, J. M. Periago Lorente (1974) se centra en un solo autor fundamental en su tesis La obra retórica del humanista hispalense Alfonso García Matamoros ${ }^{32}$ que ilustra el contenido de varias obras del mencionado humanista.

Esteban Torre aborda en 1980 el estudio de las doctrinas del Humanismo español sobre el discurso desde una original perspectiva: rastrea los supuestos de poética y retórica que se encuentran en textos de la época que no son poéticas o retóricas. Sobre lengua y literatura en el pensamiento científico español de la segunda mitad del siglo XVI es el título de la tesis ${ }^{33}$.

Por las mismas fechas se presentaron en la Universidad Complutense de Madrid las tesis de licenciatura La Retórica de Hebrera y Esmir (1981) de José Eugenio Mateo y La Retórica de Tomás Aguilar (1984) de Alfonso Sánchez-Rey.

${ }^{28}$ Edición Nacional, Madrid, CSIC, 6 vols., II, 1940, págs. 145-203.

29 Vid., p. e., D. P. Abbot, «La retórica y el renacimiento: An overview of Spanish Theory», en J. Murphy (ed.), Renaissance Eloquence: Studies in the Theory and Practice of Renaissance Rhetoric, University of California, Berkeley, 1983, págs. 95-104. K. Kohut, «Retórica, poesía e historiografia en Juan Luis Vives, Sebastián Fox Morcillo y Antonio Llull», Revista de literatura, 104, 1990, págs. 345-374.

${ }^{30}$ Madrid, Gredos, 1972.

${ }^{31}$ Publicada con el título La retórica española de los siglos XVI y XVII, Madrid, CSIC, 1973.

${ }^{32}$ Se trata de una tesis doctoral inédita.

${ }^{33}$ Sevilla, Universidad, 1984. 
Además, otros estudios sobre humanismo nos ofrecen noticias de nuestros retóricos: así, por ejemplo, la obra Juan Lorenzo Palmireno (1524-1579). Un humanista aragonés en el Studi General de Valencia que publica A. Gallego Barnés ${ }^{34}$ trata sobre este profesor de retórica valenciano.

Con fecha de 1983, aunque aparecida mucho más tarde, encontramos una entrega de la revista Dispositio que contiene un apartado sobre retórica española del siglo XVI inspirado por Luisa López Grigera. La Bibliografía ofrecida en dicho número por el Rhetorical Seminar ${ }^{35}$, formado por V. Arizpe, I. Corfis, D. Korn, P. Lasarte, F. Morrison, D. Pollard, M. Sigler y M. Thomas, ha resultado de consulta indispensable para llevar a cabo el presente trabajo. Se identifican allí 33 artes rhetoricae, 15 artes concionandi y 5 artes dictaminis del siglo XVI, indicando los diversos ejemplares localizados a través de los mejores repertorios, así como las bibliotecas donde se pueden encontrar, y las signaturas.

Los años noventa han conocido una magnífica floración de estudios sobre nuestro asunto. La excelente tesis de Elena Artaza titulada $\mathrm{El}$ 'ars narrandi' en el siglo XVI español ${ }^{36}$ se puede considerar la señal de salida para una pléyade de investigadores que se han lanzado a rastrear el panorama de las retóricas españolas del siglo XVI con idea de dejar bien descrito el mapa intelectual del momento (ciceronianos, ramistas, hermogenianos, erasmistas, etc.) y realizar la labor filológica de poner en servicio un corpus importante y semiolvidado. La misma autora culmina su empeño con una muy importante aportación reciente, antes citada a otro propósito, la Antología de textos retóricos españoles del siglo $\mathrm{XVI}^{37}$, que ofrece un volumen completo de la retórica de aquel momento (progymnasmata más tratado teórico) a base de la traducción del latín de cada parte de la doctrina retórica, extraída en cada caso del autor que le parece haber tenido mayor fortuna en la correspondiente exposición y anotada con envidiable rigor.

Detrás de esta iniciativa está también la labor ya mencionada de Luisa López Grigera que, por su parte, recoge en un libro de 1994 diversos artículos de su trayectoria ${ }^{38}$.

\footnotetext{
34 Zaragoza, Institución Cultural Fernando el Católico, 1982.

${ }^{35}$ Lo citaremos habitualmente con la abreviatura Rh.S. La bibliografia comprende las págs. 25-64.

36 Bilbao, Universidad de Deusto, 1989.

${ }^{37}$ Bilbao, Universidad de Deusto, 1997.

${ }^{38}$ En particular nos referimos al, a nuestros efectos, importante «Introducción al estudio de la retórica del siglo XVI en España», Nova Tellus, México, 1984, págs. 93-111. Traducido al inglés en el número ya citado de la revista Dispositio. También con el título «Corrientes y generaciones en la retórica del siglo XVI en España», en La retórica en la España del siglo de Oro, Salamanca, Universidad, 1994, págs. 49-60.
} 
Por nuestra parte, cabe mencionar las tesis doctorales de Luis Alburquerque García (1993), La Retórica de la Universidad de Alcalá. Contribución al estudio de la teoría literaria hispánica del siglo $X V 1^{39}$ y la de Ángel Luis Luján Atienza (1997) Retóricas españolas del siglo XVI: El foco de Valencia $^{40}$ que, junto a otras en elaboración, describen y valoran amplios territorios del conjunto que entre todos investigamos.

Como aportaciones de otros equipos, señalemos todavía la obra de Luis Merino Jerez, La pedagogía en la retórica del Brocense ${ }^{41}$, el volumen coordinado por José M. Maestre y Joaquín Pascual Barea, Humanismo y pervivencia del mundo clásico $^{42}$, el libro de Victoria Pineda, La imitación como arte literario en el siglo XVI español ${ }^{43}$ que contiene el diálogo De imitatione de Sebastián Fox Morcillo sobre el tópico por excelencia de la cultura de su tiempo ${ }^{44}$, la tesis de J. J. Prior García (1994) sobre La Retórica del 'docere', leída en la Universidad de Murcia y el libro de Alfonso Martín Jiménez, $R e$ tórica y literatura en el siglo XVI: el Brocense ${ }^{45}$.

Prescindimos en esta enumeración de los trabajos monográficos que señalaremos en el siguiente apartado, así como de aquellas traducciones y estudios de retórica antigua (los del prof. Sancho Royo ${ }^{46}$, por ejemplo) cuya incidencia sobre el panorama que se está configurando es de la mayor importancia. Tampoco abordamos la continuación de estos estudios sobre siglos posteriores ${ }^{47}$.

Volvamos al principio. Nos queda decir que la revisión que abajo presentamos de las retóricas conservadas en la Biblioteca Nacional de Madrid componen un elenco sobre el que poder trabajar en el propósito arriba enunciado. Las noticias que ofrecemos servirán para formarse opinión de la oportunidad de incluir o no un texto (por la existencia o no de traducción y de edición asequible) en el conjunto que se piensa editar. En cada entrada se consigna la signatura que actualmente posee en la BNM. Cuando ha variado respecto de la lista ofrecida por el Rhetorical Seminar, llamamos la atención del cambio con un asterisco. Cuando el texto encontrado no figuraba en este elenco anterior o, figurando, no se daban las signaturas de la BNM, señalamos la adición con dos.

\footnotetext{
${ }^{39}$ Revisada y publicada como libro con el título de El Arte de hablar en público. Seis retóricas famosas del siglo XVI, Madrid, Visor, 1995.

${ }^{40}$ En prensa en la editorial del CSIC.

${ }^{41}$ Cáceres, Institución Cultural 'El Brocense'/Universidad de Extremadura, 1992.

42 Alcañiz, Instituto de Estudios turolenses, 1993.

${ }^{43}$ Sevilla, Diputación Provincial, 1994.

${ }^{44}$ Para la perspectiva desde la poética, véase A. García Galiano, La imitación poética en el Renacimiento, Kassel, Reichenberger, 1992.

45 Valladolid, Universidad, 1997.

${ }^{46}$ Sobre el decoro de la poética, Madrid, Ediciones Clásicas, 1994 y Sobre el estilo. Libro sexto del 'Sobre el discurso', Huelva, Universidad, 1997.

${ }^{47}$ Por ejemplo la excelente tesis de R. M. ${ }^{a}$ Aradra, De la retórica a la teoría de la literatura (siglos XVIII-XIX), Murcia, Universidad, 1997.
} 
RetóRICAS EN LA BiblioteCa NACIONAL DE MADRID

ALONSO DE HERRERA, Fernando.

- Opus absolutissimum rhetoricorum Georgii Trapezuntii cum additionibus herrariensis, Compluti, 1511.

BNM: R/13543; R/17065.

ARIAS MONTANO, Benito.

- Rhetoricorum libri IIII Benedicti Ariae Montani Theologi, ac poetae laureati ex disciplina militari divi Iacobi Ensigeri; Ad Gasparem Velesium Alcocerum. Cum Annotationibus Antonii Moralii Episcopi Meschuacanensis, quae rem omnem quam brevissimme explicant, Antuerpiae, 1569. BNM: 3/16002; U/7203.

Esta obra ha tenido numerosas reediciones. Actualmente contamos con una edición moderna de María Violeta Pérez Custodio ${ }^{48}$.

- Hay también otras ediciones modernas: Benito Arias Montano, Tractatus de figuris rhetoricis, cum exemplis ex sacra Scriptura petitis ${ }^{49}$. Previamente, en 1984, se había publicado en la revista La Ciudad de Dios ${ }^{50}$.

BARDAXÍ, Francisco Juan.

- De conscribendis epistolis liber unus, Valentiae, 1564.

BNM: R/26014 $4^{51}$ y R/20707.

El estudio de esta obra forma parte de la tesis doctoral de Ángel Luis Luján.

BLAS (BLASCO) GARCÍA, Vicente.

- Brevis epitome in qua praecipua Rhetoricae capita tanquam flosculi quidam sedula manu collecti continentur, Valencia, 1581. Ejemplar R/27962 de la BNM que no tiene portada.

- Hay una edición anterior de esta obra que aparece en el tomo encabezado por Dialogus de prosodia, editada en Valencia, 1578. BNM: R/27955**. Su estudio se incluye en la tesis doctoral citada de Ángel Luis Luján.

\footnotetext{
48 «Rhetoricorum libri quattuor» de Benito Arias Montano. Introducción, edición crítica, traducción y notas (prólogo de Juan Gil), Badajoz, Departamento de Publicaciones de la Diputación Provincial de Badajoz/Servicios de Publicaciones de la Univ. de Cádiz, 1984. Aunque la fecha de edición que consta en el volumen es la de 1984 evidentemente se trata de un error y debe entenderse 1994.

49 Estudio, edición, traducción y notas de Luis Gómez Canseco y Miguel A. Márquez Guerrero, Huelva, Universidad/Madrid, Clásicas, 1995.

${ }^{50}$ Con introducción y notas de Octavio Uña. Vol. 197, 2/3, págs. 503-553.

${ }^{51}$ Según el catálogo de Rh.S. (D1, pág. 59), falta el folio 13 de este ejemplar. Hemos podido comprobar que no se trata de una falta sino de un error en la numeración, que salta del fol. 12 al 14, sin que esto afecte a la integridad de la obra.
} 
BORJA, Francisco de.

- Tratado breve para los predicadores del Santo Evangelio, Madrid, Madrigal, 1592.

En la BNM hay un ejemplar de una edición de principios de siglo de esta obra: Tratado breve y provechoso del modo de predicar el Santo Evangelio... Seguido de los documentos que dió a un predicador el Beato Alonso de Orozco, Madrid, Imprenta del Asilo de la Santísima Trinidad, 1908. BNM: V C $\mathrm{C}^{\mathrm{a}}$ 12.294-13.

- Existe un De ratione concionandi libellus que es traducción al latín del libro anterior (Rh.S. C1.3, pág. 50). Este libro se incluye como «liber decimus» (págs. 469-477) en Sancti Francisci Borgiae Opera Omnia, Bruxellis, 1675. BNM: 2/5213**.

BOSSULO, Mateo.

- Institutionum oratoriarum libri tres, Valentiae, 1566. BNM: R/25984**.

Se trata de la obra no inventariada de un retórico francés, pero que fue profesor de la Universidad de Valencia durante los años 1564-1565 ${ }^{52}$. Ángel Luis Luján la ha rescatado recientemente ${ }^{53}$.

BRAVO, Bartolomé.

- De arte oratoria ac de eiusdem exercendae ratione. Tullianaque imitatione varia ad res singulas adhibita exemplorum copia libri quinque, Methumnae a Campo, 1596. BNM: R/25986; R/25993.

- Liber de conscribendis epistolis cum singulis cuiusque generis epistolarum exemplaribus, Pompelonae, 1589.

BNM: R/29241. En este mismo tomo hay encuadernados unos progymnasmata de que ya daba noticia Antonio Martí ${ }^{54}$ : Progymnasmata sive praexercitationes oratoriae cum singulis cuiusque progymnasmatis exemplaribus.

Existe también una edición posterior fechada en Burgos, 1601. BNM: 3/46916**.

CIRUELO, Pedro.

- De arte praedicandi. Este libro aparece incluido en Expositio Libri Missalis per egregia... Addita sunt tria... opuscula. De arte praedicandi, de arte memorandi, et de correctione kalendarii..., Compluti, 1528. BNM: $\mathrm{R} / 15444 ; \mathrm{R} / 20166 ; \mathrm{R} / 20876$.

\footnotetext{
${ }^{52}$ Cfr. J. Teixidor y Trilles, Estudios de Valencia. Historia de la Universidad hasta 1616 (ed. de Laureano Robles), Universidad de Valencia, 1976.

53 «La retórica hallada de Mateo Bossulo», Revista de Literatura, LX, 119, 1998, págs. 31-43.

${ }^{54}$ Op. cit., pág. 313.
} 
COSTA Y BELTRÁN, Juan.

- De utraque inventione oratoria \& dialectica libellus, Pompeiopoli, 1570. R/15369; R/27974.

Este libro se halla encuadernado con la obra de Vives Ad sapientiam introductio, Salmanticae, 1572; BNM: R/30459. En este tomo se encuentra además la obra del Brocense: De arte dicendi liber unus denuo auctus et emendatus cui accessit in artem poeticam Horatii per eundem autorem brevis elucidatio, Salmanticae, 1558.

ESPINOSA DE SANTAYANA, Rodrigo.

- Arte de retorica en el qual se contienen tres libros. El primero enseña el arte generalmente. El segundo particularmente, el arte de Hystoriador. El tercero escrivir Epistolas y Dialogos, Madrid, 1578. BNM: R/3744; $\mathrm{R} / 327$.

Ediciones el Crotalón tiene proyectada una nueva edición de esta retórica ${ }^{55}$.

ESTELLA, Diego de.

- Modus concionandi, Salmanticae, 1576. R/30443.

Hay otra edición de esta obra: De modo concionandi liber, Coloniae, 1586. BNM: $3 / 56059^{* *}$.

Contamos también con una edición moderna: Modo de predicar y Modus concionandi, estudio doctrinal y edición crítica por Pío Sagüés Azcona, O. F. M, Madrid, C.S.I.C., 1951.

FOX MORCILLO, Sebastián.

- De imitatione seu de formandi styli ratione. Libri III, Antuerpiae, 1554. BNM: R/27976.

Existe una edición moderna de Victoria Pineda ${ }^{56}$.

FURIÓ CERIOL, Fadrique.

- Institutionum rhetoricarum libri tres, Lovanii, 1554.

BNM: R/33977; R/27595.

De esta obra traduce Elena Artaza el capítulo sobre «La causa» ${ }^{57}$; un estudio se incluye dentro de la tesis doctoral de Ángel Luis Luján.

Aparte del artículo de Dorald W. Blezwick ${ }^{58}$, tenemos constancia de que en la Universidad de Valencia hay un grupo de investigación trabajando so-

\footnotetext{
${ }^{55}$ Cfr. J. A. Mayoral, art. cit., pág. 97.

${ }^{56}$ La imitación como arte literario en el siglo XVI español, Sevilla, Diputación Provincial, 1994.

${ }^{57}$ Antología de textos retóricos españoles del siglo XVI, págs. 122-131.

58 «Las Institutiones Rhetoricae de Fadrique Furió», Nueva Revista de Filología Hispánica, 13, 1959, págs. 334-339.
} 
bre la figura de Furió Ceriol ${ }^{59}$. Se ha publicado ya el primer tomo de la obra completa: Fadrique Furió Ceriol, Opera omnia $I^{60}$. Este volumen primero contiene: El concejo y consejeros del príncipe y Bononia.

De este autor se está ocupando también David Puerta Garrido ${ }^{61}$, de cuyo trabajo ha dado un adelanto con una breve descripción de la retórica del valenciano.

GALLÉS (GALÉS), Francisco.

- Epitome troporum ac schematum et grammaticorum et rhetorum ad autores tum prophanos tum sacros intellegendos non minus utilis quam necessaria. Francisco Galesio rhetoricae eximio professore collectore, Valentiae, 1553.

Esta obra está encuadernada con la obra de Jaime Falcó Epigrammata quibus nunc denuo accesserunt alia multa tum ab eruditissimmis huius nostrae Academiae Valentinae filiis, Valentiae, 1647. BNM: R/27621**.

GARCÍA MATAMOROS, Alfonso.

- De ratione dicendi libri duo, Compluti, 1548. R/27926; R/27573; $\mathrm{R} / 27951$.

De esta obra traduce Elena Artaza el capítulo correspondiente a la «Narración epidíctica» ${ }^{62}$.

- De tribus dicendi generibus sive de recta informandi styli ratione commentarius cui accessit de Methodo concionandi liber unus eiusdem authoris, Compluti, 1570. R/27932; R/27973.

Elena Artaza traduce también los capítulos que tratan de «Los estilos ciceronianos» $\mathrm{y}$ 《Del ritmo y de los periodos» ${ }^{63}$.

Existe una edición del siglo XVIII a cargo de F. Cerdá y Rico: Alphonsi Garsiae Matamori hispalensis et rhetoris primarii complutensis Opera Omnia nunc primum in unum corpus coacta. Accedit commentarius de vita et scriptis auctoris, Madrid, Imprenta Andres Ramirez, 1769.

\footnotetext{
${ }^{59}$ M. Almenara Sebastiá, «Documentación testamentaria del Humanista Valenciano Fadrique Furió Ceriol (1527-1592). Edición y Comentario», en Estudis, 21, 1995, págs. 89-112. «Este trabajo está enmarcado en el proyecto de investigación sobre Furió Ceriol, dirigido por el Dr. Jordi Pérez Durá, en el que también forma parte el prof. Dr. Méchoulan, de París, especialista en la obra de Furió Ceriol. Es un avance, a nuestro entender clarificador, sobre la biografia y personalidad de Frederic Furió Ceriol, en versión castellana Fadrique Furió Ceriol, que se completará con la edición de las Obras de Furió Ceriol y que preparará el equipo de investigación antes mencionado» (pág. 89).

${ }^{60}$ J. Pérez Durán y H. Méchoulan (coord.), Valencia, Edicions Alfons El Magnànim, 1996.

61 «Fadrique Furió de Ceriol: aproximación a su obra retórica», en J. M. Maestre y J. Pascual Barea (coord.), Humanismo y pervivencia del mundo clásico, op. cit., vol. I.2, 1993, págs. 851-856.

${ }_{62}$ Antologia de textos retóricos españoles del siglo XVI, págs. 117-121.

${ }^{63}$ Ibidem, págs. 177-194 y 194-201 respectivamente.
} 
El estudio de ambos volúmenes puede verse tanto en la tesis de Periago Lorente como en el libro de Alburquerque García, el cual proyecta realizar una traducción anotada de la obra completa de este autor.

Existe una edición y traducción inédita del De tribus dicendi generibus. Fue tesis doctoral de M.A. Rábade Navarro, presentada en Sevilla en 1990.

GRANADA, Luis de.

- Ecclesiasticae rhetoricae sive de ratione concionandi, Olysippone, 1576. BNM: R/28117*; como se señala en el catálogo del Rh.S. (C5.1, pág. 52) el colofón está fechado en 1575 .

De esta obra reproduce Elena Artaza la traducción de Josef Climent (1778) del capítulo que corresponde a las «Virtudes elocutivas» ${ }^{64}$. Tenemos además una traducción de esta obra ${ }^{65}$.

GUEVARA, Pedro de.

- Escala del entendimiento en la qual se declaran las tres Artes... de Gramática, Dialectica, Retorica, y la universal para todas las sciencias, Madrid, 1593. BNM: R/28147.

Esta obra se halla encuadernada con otra del mismo autor: Nueva y sutil invencion, en seys instrumentos, [...] con la cual facilissimamente y en muy breve tiempo se aprendera todo el artificio, y estilo de las gramaticas..., Madrid, s.a. BNM: R/10461.

GUZMÁN, Juan de.

- Primera parte de la Rhetorica, Compluti, 1589. BNM: R/1454; R/716.

De esta obra reproduce Elena Artaza el capítulo correspondiente a la «Chría» ${ }^{66}$.

También puede consultarse un estudio de esta obra en el libro de Luis Alburquerque. Contamos, además, con dos ediciones modernas de esta retórica: la de Blanca Periñán ${ }^{67}$ y la preparada por ediciones «El Crotalón» ${ }^{68}$.

LAX, Gaspar.

- De arte inveniendi medium tractatum, Parisiis, 1512. Este libro aparece citado en el catálogo del Rh.S. (R16, 1 y 2, págs. 30-31), pero no está en la Biblioteca Nacional de Madrid.

\footnotetext{
${ }^{64}$ Ibidem, págs. 151-177.

${ }^{65}$ Obras de VPM Fray Luis de Granada, tomo III, Ediciones Atlas, Madrid, 1945. Los seis libros de la retórica Eclesiástica o de la manera de predicar, págs. 488-642.

${ }_{66}^{6}$ Antología de textos retóricos españoles del siglo XVI, págs. 34-38.

${ }^{67}$ Juan de Guzmán, Primera parte de la rhetorica (Alcalá de Henares, 1589), (introducción, texto crítico y notas), Pisa, Giardini Editori, 1993, 2 vols.

68 Juan de Guzmán, Primera parte de la Rhetorica, Madrid, 1994.
} 
Hemos podido consultar, sin embargo, dos libros de este autor: Exponibilia correcta et remisa per ipsum, París, 1512 (BNM R/19977); y Tractatus de materiis et de oppositionibus in generali, Parisius, s.a (R/20167). Por lo demás, el título De Arte inveniendi evoca más bien la posibilidad de un contenido dialéctico.

LAYNEZ, Diego.

- Tabella brevis pro concionatorum instructione. Esta obra sólo aparece citada en el catálogo del Rh.S. (C6.1, pág. 54) que toma la referencia de Nicolás Antonio.

No hemos hallado la obra en la BNM, pero puede consultarse una bibliografia sobre este autor de José Antonio Pérez Rioja ${ }^{69}$.

LLULL, Antonio.

- De oratione libri septem, Basileae, 1558. La fecha de edición que se da es la del colofón, pues la portada aparece sin número de año. BNM: R/38749**. En el estudio de esta obra trabaja actualmente Luis MartínezFalero en la Universidad Complutense de Madrid.

De esta obra traduce Elena Artaza el capítulo correspondiente a la «Narración forense» ${ }^{70}$.

Han aparecido recientemente dos ediciones parciales de la obra de este autor, hechas ambas por Antonio Sancho Royo ${ }^{71}$.

- Progymnasmata rhetorica, Basileae, 1550. Por información de Luis Martínez-Falero sabemos que un ejemplar de otra edición de esta obra (Basilea, 1551) se encuentra microfilmado en la Facultad de Filología de la Universidad Complutense de Madrid.

Elena Artaza traduce los capítulos que tratan de la «Narratiuncula», del «Encomio», de la «Comparatio», de la «Amplificatio» y de la «Tesis» ${ }^{72}$.

NAVARRA, Pedro de.

- Diálogos de la diferencia del Hablar al Escribir, Tolosa, 1560.

En el elenco del Rh.S. (R18.1, pág. 31) se consigna una edición de esta obra: Diálogos de la diferencia del hablar al Escribir, Tolosa, Colomar, 1560 en la Biblioteca de la RAE: R-78.

\footnotetext{
${ }^{69}$ Una bibliografia en torno al P. Diego Lainez, Soria, Centro de Estudios sorianos, CSIC, Patronato «José María Quadrado», 1966.

${ }^{70}$ Antología de textos retóricos españoles del siglo XVI, págs. 96-116.

${ }^{71}$ Sobre el decoro de la poética, Madrid, Ediciones Clásicas, 1994 y Sobre el estilo. Libro sexto del 'Sobre el discurso', Huelva, Universidad, 1997.

72 Antología de textos retóricos españoles del siglo XVI, págs. 32-34, 54-58, 58-61, 68-74 y $75-79$ respectivamente.
} 
Hemos localizado un ejemplar en la BNM encuadernado con otros diálogos del autor, el primero de los cuales lleva por título Dialogos de la eternidad del anima dirigidos al beatissimo padre Papa Pio quarto, Tolosa, s.a. (1565). El segundo diálogo aparece con su portada propia: Dialogos de la differencia del hablar al escrevir (materia harto sotil y notable), Tolosa, en casa de Iacobo Colomerio, s.a. R/5756**.

Aparece igualmente en BNM una edición moderna. Dialogos de la differencia del hablar al escrevir (materia harto sotil y notable) Tolosa, Iacobo Colanerio (s.a. 1560?), D. O. Chamber Editor (s.l. Berkeley, s.i.), 1968. BNM: V C C $^{\mathrm{7}}$ 7848-18.

NEBRIJA, Elio Antonio de.

- Artis rhetoricae compendiosa coaptatio ex Aristotele, Cicerone, Quintiliano, Compluti, 1515. BNM: R/1775.

Elena Artaza traduce el capítulo correspondiente al «Exordio» ${ }^{73}$. También puede verse un estudio en el libro de Luis Alburquerque.

NÚÑEZ, Pedro Juan.

- Institutiones oratoriae collectae methodicos ex institutionibus prioribus Audomari Talaei, auctore Petro Joanne Nunnesio, valentino, Valentiae, 1552. Esta edición aparece citada en el catálogo del Rh.S. (R20.1, pág. 32) en coincidencia con la fecha que da Ximeno ${ }^{74}$.

Hemos encontrado en la BNM la edición que Mayáns hace de esta obra: Institutiones oratoriae collectae methodicos ex institutionibus prioribus Audomari Talaei, auctore Petro Joanne Nunnesio, valentino. Accedunt eiusdem annotationes: ipsiusmet tabulae rhetoricae, quaestio de componendis epistolis, in quibus de Gratiarum actione disputetur, et eidem vindicata oratiuncula in Scholis recitari solita. Ex Bibliotheca Majansiana, Valentiae Edetanorum, apud Franciscum Burguete, 1774. BNM: 2/49422; 2/15458; 2/25810.

- Progymnasmata id est praeludia quaedam oratoria ex progymnasmatis potissimum Aphthonii dictata a Petro Ioanne Nunnesio Valentino, Caesaraugustae, apud Michaelem Eximinum Sanchez, 1596. BNM: R/29803**. Al final de este volumen hay un arte epistolar: Ratio brevis et expedita conscribendi genera epistolarum illustriora.

Conocemos una edición de esta obra realizada por Vicente Ferrer en el siglo XVII: Breves progymnasmatum Petri Nunnessi et Rhetorica Francisci Novellae institutiones ex variis eiusdemque artis scriptoribus. Nunc denuo

\footnotetext{
73 Ibidem, págs. 85-88.

${ }^{74}$ Escritores del Reyno de Valencia, chronológicamente ordenados desde el año 1238 de la Christiana conquista de la misma ciudad hasta el de 1747, Valencia, 1747-49, 2 vols., I, pág. 223.
} 
aliquot Mendis repurgata et novis tabulis alumnis utilibus illustrata a Vicentio Ferrer Gandiensi, Diacono in Valentina Academia prima Rhetorica Cathedra Praefecto, Valencia, 1655. Biblioteca Universitaria de Valencia: 33/42.

- Institutiones rhetoricae ex progymnasmatis potissimum Aphthonii atque ex Hermogenis arte dicatatae a Petro Ioanne Nunnesio Valentino, Barcinone, 1578. BNM: R/28482; R/29438; R/29826.

- Petri Johanni Nunnesii valentini institutionum Rhetoricarum libri quinque. Editio altera multo correctior et locupletior exemplis et indicibus et nova accesione artificii, quo possit ars copiosius et utilius exerceri, Barcinone, 1585. BNM: R/29590; R/29425.

- Pet. Iohan. Nunnesii Valentini Institutionum Rhetoricarum libri quinque. Editio Tertia ceteris multo correctior et locupletior exemplis et indicibus et nova accessione artificii, quo possit ars copiosius et utilius exerceri, Barcinone, 1593. BNM: R/28477*.

De esta última edición de la obra de Núñez Elena Artaza traduce los capítulos que tratan de la «Fábula», la «Sentencia», el «Lugar común», la «Etopeya», la «Legislatio» todos ellos pertenecientes a la parte de los progymnasmata, y el capítulo que trata «De las 'ideas' o estilos del decir» ${ }^{75}$.

Ximeno ${ }^{76}$ nos da noticia de que la obra retórica de Núñez, sin indicar la edición, fue traducida al castellano en 1624 por Miguel Sebastián, «Presbítero, Cura de la Iglesia de Galve, dicipulo que avia sido de Núñez; pero esta versión quedó Ms. y asi la vio D. Nicolas Antonio»» ${ }^{77}$.

- Tabulae institutionum rhetoricarum Petri Iohannis Nunnesii Valentini, Barcinone, 1578. Esta edición aparece citada en el catálogo del Rh.S. (R20.6, pág. 33), pero no aparece en la BNM. En esta Biblioteca aparece una edición (que se presenta como tercera) de 1599: Tabulae institutionum rhetoricarum Petri Iohannis Nunnesii Valentini. Tertia editio multo accuratior prioribus, Valentiae, 1599. BNM: R/28455. Mayáns editó también estas tablas.

- Apposita Marci Tulii Ciceronis, Valentiae, 1556. Se trata de una lista de adjetivos que usó Cicerón aplicados a sus correspondientes sustantivos. BNM: R/29827; R/29549**.

- Manuscrito de BNM: ms. 9153**, titulado Institutiones oratoriae ex variis scriptoribus ac praesertim ex Hermogene auctore Petro Ioanne Nunnesio Valentino ${ }^{78}$.

\footnotetext{
${ }^{75}$ Antología de textos retóricos españoles del siglo XVI, págs. 27-31, 38-41, 49-54, 61-63, 79-83 y 201-256 respectivamente.

76 Escritores del Reyno de Valencia, chronológicamente ordenados desde el año 1238 de la Chrstiana conquista de la misma ciudad hasta el de 1747, I, pág. 223.

77 Vid. N. Antonio, Bibliotheca Hispana Nova, pág. II, 205.

${ }^{78}$ Vid. F. Grau Codina, Las retóricas de Pedro Juan Núñez (ediciones y manuscritos), Universidad de Valencia, 1995 (microfichas), págs. 455-556.
} 
- Por último, hay dos manuscritos de trabajos atribuidos a Núñez sobre el arte epistolar. El primero se titula «Formulae illustriores ad praecipua genera epistolarum conscribenda. Simul cum praeceptis quibus fere uti solet M. T. Cicero» y ocupa los folios $97 \mathrm{r}$ a $158 \mathrm{v}$ del manuscrito $7227^{* *}$ de la BNM que se abre con el Tractado de los Reyes de Granada y su Origen de Hernando del Pulgar. El segundo trabajo se encuentra en los folios $63 \mathrm{v}-$ 66r del manuscrito $152^{* *}$ de la BNM titulado «Perafer (sic) censura de una epistola se han de considerar tres coses».

Tenemos una edición de estos textos en la tesis doctoral de Ferrán Grau Codina $^{79}$. El estudio de la mayor parte de ellos se incluye en la tesis de Ángel Luis Luján.

PALMIRENO, Juan Lorenzo.

Sobre las obras numerosísimas de Palmireno puede verse la bibliografía que da Gallego Barnés ${ }^{80}$ al final de su libro, y la de Latassa ${ }^{81}$. Además, hay una tesis inédita de Miguel Artigas titulada Estudio biográfico-bibliográfico-crítico de Juan Lorenzo Palmireno y sus obras que se puede consultar, según Antonio Martí ${ }^{82}$, en la Biblioteca de la antigua Universidad madrileña en la calle de San Bernardo. Recogeremos aquí las obras puramente retóricas.

- Aphthonii clarissimi rhetoris progymnasmata Ioanne Maria Cataneo interprete, nunc denuo recognita iuxta veritatem graeci exemplaris et scholiis illustrata per Ioanne Laurentium Alcannizensem ludimagistrum valentinum et Hieronymum Fibotae dicata. Accesit etiam ex Hermogenis sententia quo modo status causae cognosci debeat, Ex officina Joannis Mey Flandri, Valentiae, 1552. Noticia de esta obra da Gallego Barnés ${ }^{83}$. Sólo conocemos el título, ya que hoy se da por perdida.

- Laurentii Palmyreni de vera et facili imitatione Ciceronis cui aliquot opuscula studiosis adolescentibus utilissima adiuncta sunt, ut ex sequenti pagella cognosces, Zaragoza, 1560 . BNM: R/8330**. Se han añadido a esta obra otros opúsculos sobre diferentes cuestiones que afectan a la escritura en latín: De ratione syllabarum, De orthographia, De notis distinguendae orationis, De notis arithmeticis Ciceronis, Lexicon puerile, Ratio facile per-

\footnotetext{
${ }^{79}$ Ibidem.

${ }^{80}$ Juan Lorenzo Palmireno (1524-1579). Un humanista aragonés en el Studi General de Valencia, Zaragoza, Institución Cultural Fernando el Católico, 1885, II, págs. 456-462.

${ }^{81}$ Bibliotecas antigua y nueva de escritores aragoneses aumentados y refundidas en forma de Diccionario Bibliográfico-biográfico por D. Miguel Gómez Uriel, Zaragoza, 1885.

${ }^{82}$ La preceptiva retórica española en el siglo de Oro, Madrid, Gredos, 1972, pág. 189.

${ }^{83}$ Juan Lorenzo Palmireno (1524-1579). Un humanista aragonés en el Studi General de Valencia, págs. 49-50.
} 
veniendi ad veram dialecticam et utramque philosophiam, Adagiorum Hispanice \& Latine loquentium centuriae quinque.

- El grueso de la obra retórica de Palmireno se va publicando por partes que después reúne en un solo volumen. Las primeras ediciones de estas partes datan de entre 1564 y 1566: Rhetoricae prolegomena, 1564; De copia rerum et artificio oratoria, 1564; De inventione, liber secundus, 1564; Rhetoricae Laurentii Palmyreni pars secunda, 1565; y Tertia et ultima pars rhetoricae, 1566 . Estas partes van reeditándose, agrupándose de distintas maneras, sufriendo modificaciones, etc.

Hemos hallado una edición compilada en 1567 y que consiste en la encuadernación en un solo tomo de las varias partes que forman el conjunto de la retórica de Palmireno: Rhetoricae prolegomena, 1567; Prima pars rhetoricae Laurentii Palmyreni Ad amplissimum virum D.D. Franciscum Caclin del Castillo Archidiaconum Setabensem, Valencia, 1567; Secunda pars rhetoricae Laurentii Palmyreni, in duos libellos distributa, quorum prior Elocutionis praecepta; alter exercitationem et exempla complectitur, Valencia, 1567; Tertia et ultima pars rhetoricae Laurentii Palmyreni, in qua de memoria et actione disputatur, Valencia, 1566. Esta última parte tiene además añadidos fragmentos de comedias y otros opúsculos de Palmireno, y sospechamos que no es más que la primera edición, porque su fecha es más temprana que las de las otras partes. BNM: R/16001; R/15643; R/15923.

- Se publican dos ediciones más de la retórica de Palmireno. La primera, De arte dicendi libri quinque, 1573; BNM: R/15636. La última, De arte dicendi libri tres. Quarta editio, 1578; BNM: R/21770.

- Dilucida conscribendi espistolas ratio, quondam Laurentio Palmyreno, nunc a Agesilao filio sedulitate in genti et aucta et emendata, Valentiae, 1585. BNM: R/24819.

Un estudio de estas obras se incluye en la tesis de Ángel Luis Luján.

PÉREZ, Juan.

- Progymnasmata artis Rhetoricae, Ioannis Petreii Toletani una cum Annotationibus in Senecae declamationes, controversias \& deliberativas, Compluti, 1539. BNM: R/28731; R/20595; R/28736**.

El estudio de esta obra se incluye en la tesis doctoral en preparación de M. a Ángeles Martínez Calvo.

PÉREZ DE VALDIVIA, Diego.

- De sacra ratione concionandi, Barcinone, 1588. BNM: R/31376; 3/2086.

PERPIÑÁ, Pedro Juan, S.I.

- De arte rhetorica discenda editado en Orationes quinque, Romae, 1565. Cita esta obra Rh.S. (R23.1-2, pág. 35). 
Antonio Marti ${ }^{84}$ recoge de este autor sus orationes duodeviginti, Lugduni, 1594, y además añade que es autor de sermones pero que no escribió ningún tratado de retórica.

Hemos consultado las Opera, Romae, 1749 (4 vols.) (BNM: 3/33480-3) y no aparece ningún arte retórica.

SALINAS, Miguel.

- Rhetorica en lengua castellana, Compluti, 1541. BNM: R/452; $\mathrm{R} / 5059 ; \mathrm{R} / 12807$.

De esta obra reproduce Elena Artaza el capítulo correspondiente a «La Memoria» ${ }^{85}$; ha sido tratada por P. E. Russel1 ${ }^{86}$ y Luis Alburquerque en su libro citado, y editada por Elena Casas ${ }^{87}$.

Según noticia de J.A. Mayoral ${ }^{88}$, Ediciones el Crotalón proyecta también editarla.

SÁNCHEZ, Gaspar.

- Conciones in Dominicis et feriis Quadragesimae, Toleti, 1597. BNM: $\mathrm{R} / 26994 ; 3 / 54542 * *$.

Existe además otra obra en BNM que no hemos visto citada en el catálogo del Rh.S. ni en Antonio Martí: Elegantes formulae ex omnibus Ciceronis operibus selectae, Pampelonae, 1590. BNM: 3/39435; 3/5780; $\mathrm{R} / 26650^{* *}$.

SÁNCHEZ DE LAS BROZAS, Francisco.

- De arte dicendi liber unus, Salmanticae, 1556. Hay una edición de esta obra de 1558 en la BNM: R/27267**.

De esta obra traduce Elena Artaza el capítulo que trata del «Epílogo» ${ }^{89}$.

- Organum dialecticum et rhetoricum, Lugduni, 1579. BNM: R/29831.

De esta obra traduce Elena Artaza el capítulo correspondiente a la «Dispositio» ${ }^{90}$.

Ambas obras han sido editadas modernamente por Eustaquio Sánchez Salor y César Chaparro Gómez ${ }^{91}$.

${ }^{84}$ La preceptiva retórica española en el siglo de Oro, pág. 238.

85 Antología de textos retóricos españoles del siglo XVI, págs. 257-260.

86 «Un libro indebidamente olvidado, La Retórica en lengua castellana (1541) de Fray Miguel de Salinas», en Libro-Homenaje a Antonio Pérez Gómez, II, Cieza, 1978, págs. $133-142$.

${ }^{87}$ La Retórica en España, Madrid, Editora Nacional, 1980, págs. 39-200.

${ }^{88}$ Art. cit., pág. 97.

${ }^{89}$ Antología de textos retóricos españoles del siglo XVI, págs. 145-147.

90 Ibidem, págs. 149-150.

91 Francisco Sánchez de las Brozas, Obras. I. Escritos retóricos, Cáceres, Institución cultural «El Brocense», Excma. Diputación provincial, 1984. 
También pueden verse sobre la retórica del Brocense los libros de Merino Jerez y Martín Jiménez ${ }^{92}$.

SANTIAGO, Juan de, S.I.

- De arte rhetorica libri quatuor: in quibus eiusdem artis praecepta artificiosa methodo explicantur ad eloquentiam comparandam ad cuius finem pro appendice additum est brevissimum opusculum de conscribendis epistolis cum indice totius operis, Hispali, Excudebat Ioannes Leonius, 1595. BNM: R/28360**.

- De methodo concionandi, Hispali, 1595. El catálogo del Rh.S. (C11, pág. 56) da esta obra y añade que, según Palau, este libro es De arte rhetorica libri quatuor.

SEGOVIA, Fray Juan de.

- De praedicatione evangelica libri quatuor, Compluti, 1573.

BNM: 2/44277; 7/12945; R/28547.

SEGURA, Martín de.

- Rhetorica institutio in sex libros distributa, Compluti, 1589. BNM: $\mathrm{R} / 29748 ; \mathrm{R} / 2804$.

Un estudio de esta obra puede verse en el libro de Luis Alburquerque.

SEMPERE, Andrés.

- Methodus oratoria item et de sacra ratione concionandi libellus, Valentiae, 1568. BNM: R/29740; R/29761.

El estudio de esta obra se incluye en la tesis de Ángel Luis Luján. La edición de la gramática de este autor hecha por Xavier Gómez i Font ${ }^{93}$ incluye una introducción extensa y bien documentada que trata también la labor retórica de Sempere.

- Tabulae breves et expeditae in praeceptiones Rhetoricae Georgii Cassandri, multis additionibus redditae auctiores, Valentiae, 1553. BNM: R/27072**.

SUÁREZ, Cipriano, S.I.

- De arte rhetorica libri tres, Conimbricae, 1562. BNM: R/30096; $\mathrm{R} / 34627^{* *}$.

${ }^{92}$ L. Merino Jerez, La pedagogía en la retórica del Brocense, Cáceres, Institución Cultural 'El Brocense'-Universidad de Extremadura, 1992. A. Martín Jiménez, Retórica y literatura en el siglo XVI: El Brocense, Valladolid, Universidad, 1997.

${ }^{93}$ Andreu Sempere (1510-1572) i la seua 'prima grammaticae latinae institutio', Alcoi, Ajuntament d'Alcoi, Institut de Cultura 'Juan Gil-Albert', 1997. 
Otra edición de esta obra, de Sevilla, 1569 lleva la signatura de la BNM: R/30093**.

De esta obra traduce Elena Artaza el capítulo que trata de «Los argumentos ${ }^{94}$.

Un estudio de esta obra puede verse en el libro de Luis Alburquerque.

TORRES, Alfonso de.

- Tabulae breves et compendiariae in duos tomos rhetoricae compositae, Compluti, 1579. Biblioteca de la RAE: 10-X-89**.

- Rhetoricae exercitationes, Compluti, 1569. BNM: 2/11348; R/30331**.

De esta obra traduce Elena Artaza los capítulos correspondientes a la "Refutatiuncula», la "Confirmatiuncula» y la «Descriptio»"

- Comentarii in quartum antonii nebrissensis editi a magistro Alfonso Torres, Compluti, 1569. BNM: R/31664**.

- Comentarii in Quintum Antonii Nebrissensis, Compluti, 1559. BNM: $\mathrm{R} / 29975^{* *}$.

El estudio de las obras de este autor se incluye en la tesis en preparación de M. ${ }^{a}$ Ángeles Martínez Calvo.

TRUJILLO, Tomás.

- Thesaurum Concionatorum, Barcinone, 1579. BNM R/30722-23.

Martí $^{96}$ dice que se trata «de una inmensa colección de materiales predicables».

Hay numerosas ediciones de esta obra en la BNM.

VALADES, Fr. Diego.

- Rhetorica christiana ad concionandi et orandi usum accommodata, Perusiae, 1579. BNM: R/2156.

Hay edición moderna de esta obra: VALADES, Diego, Retórica cristia$n a$, introducción de Esteban J. Palomera, México, FCE, 1989. (Reproducción facsimilar de la Ed. de Roma, 1579).

VILLAVICENCIO, Lorenzo.

- De formandis sacris Concionibus seu de interpretatione Scripturarum populari libri III, Antuerpiae, 1565. BNM: R/26802; R/31653**.

Se encuentra encuadernada con De recte formando theologiae studio, Antuerpiae, 1565. BNM: 3/19444; 7/13317**.

\footnotetext{
94 Antología de textos retóricos españoles del siglo XVI, págs. 131-145.

${ }^{95}$ Ibidem, págs. 42-46, 46-49 y 63-68 respectivamente.

${ }^{96}$ La preceptiva retórica española en el siglo de Oro, pág. 331.
} 
VIVES, Juan Luis.

- De ratione dicendi libri tres, Coloniae, 1537. Hay en la BNM una edición de 1536: Rhetoricae sive de recte dicendi ratione libri tres, Basileae, 1536. BNM: R/30440**.

De esta obra traduce Elena Artaza el capítulo que trata de la «Narración histórica» ${ }^{97}$.

Las obras retóricas de Vives están traducidas en las obras completas editadas por Lorenzo Riber ${ }^{98}$.

También se ha comenzado una edición de sus obras completas: Juan Luis Vives, Opera Omnia, Alacant, Edicions Alfons el Magnànim, 1992.

- Hay una edición moderna del tratado De conscribendis epistolis de Charles Fantazzi ${ }^{99}$. BNM: 3/173884.

ZÚÑIGA, Diego de.

- Philosophiae prima pars qua perfecte \& elegante quatuor scientiae Metaphysica, Dialectica, Rhetorica \& Physica declarantur, Toleti, 1597. BNM: R/28812**.

ENvío

En resumen: el conjunto de razones que dejamos expuestas al principio avala nuestro propósito de incrementar los estudios de retórica, la significación y número de los manuales del siglo XVI posibilitan un modo concreto de lograr ese incremento (a saber: la traducción y edición de sus textos) y los fondos de la Biblioteca Nacional de Madrid que consignamos nos ofrecen un lugar por donde empezar la tarea.

Esperamos la colaboración de la comunidad profesional a la que desde aquí pedimos ayuda para concretar cuáles han de ser las obras que constituyan la primera colección de retóricas del siglo xvi cuya publicación abordemos (se encuentren en la Biblioteca Nacional de Madrid o no) y con qué colaboraciones podemos contar para, entre todos, tener a punto las mencionadas ediciones. Luego, podemos seguir con los fondos del siglo XVII.

Sin duda, habrá más de un ejemplar que tengamos nosotros traducido y que también lo tengan otros preparado para la edición. No es siempre malo que se duplique el trabajo, pues muchas veces será ocasión de fecunda

\footnotetext{
${ }^{97}$ Antología de textos retóricos españoles del siglo XVI, págs. 88-96.

98 Juan Luis Vives, Obras completas (primera traslación castellana integra y directa, comentarios, notas y un ensayo bibliográfico), Madrid, Aguilar, 2 vols., 1947-48.

${ }_{99}$ Juan Luis Vives, De conscribendis epistolis (critical edition with introduction, translation and annotation), Leiden, E. J. Brill, 1989.
} 
controversia. De todas maneras, este envio tiene por objeto que se sumen esfuerzos, de forma que el conjunto de la tarea pueda ser culminada en poco tiempo, aprovechando las energías de los medios académicos españoles de las áreas de filología clásica e hispánica, de lingüística general y teoría de la literatura. Esta aportación recaba crítica y correspondencia para llevar a cabo un trabajo interdisciplinario y solidario. $Y$ muy interesante según creemos. 